\title{
Operaciones secretas inglesas en España durante la Segunda Guerra Mundial
}

\author{
Michael Alpert
}

\begin{abstract}
RESUMEN
ABSTRACT

Algunos miembros de los servicios ingleses de Información involucrados

en la Guerra Civil, sobre todo Kim Philby y el capitán de Navío Hillgarth, siguieron ocupando cargos de importancia en los servicios secretos durante la Segunda Guerra Mundial.

Las principales actividades de los servicios secretos ingleses en España

incluían preservar la seguridad de Gibraltar, contrarrestar el trabajo de los agentes alemanes en el Estrecho, $y$ desenmascarar a los espias españoles dirigidos por el Abwehr. Este artículo

se ocupa especialmente de las dificultades de organizar el trabajo del llamado Special Operations Executive,

en relación con la planificación de actividades guerrilleras y de sabotajes en caso de una ocupación de España

por fuerzas militares alemanas.

PALABRAS CLAVE

España, Gran Bretaña, Alemania, Segunda Guerra Mundial, Información secreta, Espionaje, Guerrilleros, Sabotajes.

British specialists such as Kim Philby and Captain Alan Hillgarth, who had been involved in Intelligence services during the Spanish Civil War, contributed to the activities of the British Secret Services in Spain during the Second World War. Their main activities included the security of Gibraltar, counteracting German Intelligence in the Straits, and unmasking Spanish agents controlled by the Abwehr. This article concentrates on the particular difficulties of organising the work of the Special Operations Executive and its plans for guerrilla-type activity in the case of a German military occupation of Spain, whose neutrality, in the view of Great Britain, had to be carefully preserved.

KEY WORDS

Spain, Great Britain, Germany, Second World War, Secret Services, Intelligence, Espionage, Guerrillas, Sabotage.
\end{abstract}




\section{PHILBY, POLLARD Y EL VUELO DEL DRAGÓN RAPIDE. LA SECCIÓN D Y LA SECCIÓN $V$.}

En otro artículo, hemos investigado con algún detalle el caso del notorio agente secreto inglés Kim Philby después de que fuera reclutado por los servicios secretos soviéticos, a quienes sirvió durante la guerra civil española bajo la cobertura de periodista en la Zona Nacional ${ }^{1}$. En ese artículo especulamos sobre si hubo algún contacto entre Philby, Luis Bolín, corresponsal del diario monárquico $A B C$ en Londres, y los ingleses que organizaron el vuelo que llevó, el 18 de julio de 1936, al general Franco desde Canarias a Tetuán.

Entre los ingleses involucrados en el viaje de Franco hubo uno, el comandante Hugh Pollard, que había estado destinado en los servicios de Información. En el artículo citado suponemos que Pollard debió desempeñar un papel en el vuelo del Dragón Rapide más importante que el de pasajero casual que los relatos suelen darle. La gran mayoría de los documentos de los servicios secretos ingleses no está abierta al público. Sin embargo, sí se han facilitado en el archivo del Public Record Office, algunos legajos sobre la actividad en el continente europeo, durante la Segunda Guerra Mundial, del Special Operations Executive o SOE ${ }^{2}$. Y entre estos documentos desordenados, que inclyen referencias fragmentarias a otros servicios de información, hemos encontrado mención de Pollard.

Pollard representaba en Madrid, en 1940 y 1941, la llamada Section D (por Destrucciones), subsección, fundada en 1938, del Special Intelligence Service o SIS - a su vez otro título empleado para describir el célebre MI (Military Intelligence) 6-encargado de espionaje y contra-espionaje en el extranjero, mientras el mejor conocido MI5 estaba encargado de actividades en territorio inglés ${ }^{3}$. La Sección $\mathrm{D}$ contaba entre sus cometidos el sabotaje en los países ocupados por Alemania ${ }^{4}$.

Michael AlPERT, «Philby y el vuelo del Dragón Rapide», La Aventura de la Historia, No. 9 , págs. 28-36.

2 En el libro más conocido sobre el tema (Foot, M. R. D. SOE: the Special Operations Executivew 1940-1946, Londres: BBC, 1984), casi no se menciona a España.

3 La confusión entre los cometidos de tantas secciones es manifiesta, debiéndose a la creación, frecuentemente ad hoc, de organismos encargados de diferentes actividades, y a las rivalidades entre ellos. En la documentación, que suponemos relativamente poca, que ha sobrevivido, el lector, por otra parte, se encuentra ante referencias a cargos en clave, lo cual imposibilita saber de que personas se trata y de la relación entre ellas. Por supuesto, el llamado "Military Intelligence" no tiene nada que ver con la información militar propiamente dicha, y refleja sólo los orígenes históricos del servicio secreto.

4 WEST, Nigel, Secret War: the Story of SOE, Britain's Wartime Sabotage Organization (Londres: Hodder and Stoughton, 1992). 
Paralelamente a la Sección D, funcionaba la Sección V del SIS, encargada del contra-espionaje. Esta sección obtenía, por métodos normalmente ilegales, su información en Madrid y otras capitales, neutrales durante la Segunda Guerra Mundial, transmitiéndola a MI5 y, en el caso de actividades alemanas que contravenían de neutralidad española, al Foreign Office. Kim Philby, ya miembro establecido de los servicios secretos ingleses, dirigía desde Inglaterra desde de septiembre de 1941 la subsección ibérica de la Section V. Su función primordial era calibrar las grandes cantidades de información que llegaban desde la Península, acerca de operaciones de espionaje montadas en suelo británico por el Abwehr, el organismo alemán de información encabezado por el almirante Canaris ${ }^{5}$, cuyas estaciones de Tánger y Algeciras transmitían valiosas informaciones.

\section{LA NECESIDAD DE MANTENER NEUTRAL A ESPAÑA}

En Londres se consideraba absolutamente primordial la preservación de la neutralidad española. La importancia estratégica de la Península Ibérica era incontable, dada su situación geográfica a caballo de las líneas de comunicación inglesas. España como miembro activo del Eje hubiera permitido a los submarinos alemanes en el Atlántico una mayor autonomía de operaciones con la consiguiente interrupción de las comunicaciones inglesas.

La cuestión importante, en los meses tensos de 1940 y 1941, era: los actos y declaraciones hostiles hacia Inglaterra por parte de España ¿deberían ser tolerados, suponiendo que el nuevo régimen no deseaba declarar la guerra a Inglaterra ni admitir el paso por su territorio de fuerzas alemanas, o bien buscaba España sólo el momento adecuado para aliarse con Hitler y, por lo tanto, debería Inglaterra realizar una operación preventiva tal como desembarcar fuerzas militares en las Islas Canarias?

Ahora bien, el embajador inglés en Madrid, Sir Samuel Hoare, reconocido pro-franquista durante la guerra civil, nombrado en junio de 1940, y convencido de que los alemanes eran capaces de derrumbar el actual gobierno de España, sustituyéndolo por ministros más favorables a una declaración de guerra, insistía que Londres debería hacer todo lo posible para apoyar al régimen español ${ }^{6}$. Hoare estaba convencido de que Fran-

5 PhILBY, Kim, My Silent War (Londres: Panther Books, 1969. Primera edición MacGibbon and Kee, 1968), págs. 47-49.

6 Véase SMYTH, Denis, Diplomacy and Strategy of Survival: British Policy and Franco's Spain 1940-41 (Cambridge: Cambridge University Press, 1986), pág. 31. 
co prefería mantener a España neutral, pese a que el Caudillo había declarado, el 13 de junio de 1940, que España se hallaba en situación de nobeligerancia, hostil a Inglaterra.

En Londres la neutralidad de España se buscaba lograr, en último têrmino, amenazando con aumentar la rigidez del bloqueo mantenido por la Marina Real, que no dejaba pasar materias primas ni alimentos a España, aunque no se podía garantizar que las importaciones no terminaran ayudando al esfuerzo alemán de guerra.

España esperaba, entrando en la guerra, ver transferida a su bandera importantes regiones del imperio norteafricano francés, además de sustanciosas remesas de materias primas. Eran éstas exigencias que Alemania encontraría muy difícil satisfacer. Las contrademandas alemanas en el sentido de permitir el establecimiento de bases en las Islas Canarias no encontraron eco favorable en Madrid, sobre todo cuando se hizo evidente que la Luftwaffe iba perdiendo, en agosto y septiembre de 1940, la batalla de Inglaterra y que por lo tanto la ocupación por los alemanes de las Islas Británicas no era tan inminente como se había supuesto antes. Dado el constante temor inglés de que España no podría resistir la presión para que fuerzas alemanas pasaran por España, y ante la imposibilidad de defende Gibraltar, la política inglesa permanecía igual: asegurar la neutralidad, animando la voluntad española de resistir las demandas alemanas. Esta política iba justificándose cada vez más, dadas las negativas alemanas de satisfacer las exigencias españolas ?, y por las dudas dentro de altas esferas del régimen franquista sobre la verdadera posibilidad de un triunfo alemán ${ }^{8}$.

\section{EL ESPIONAJE: PAPEL DE HILLGARTH}

Una de las ventajas de mantener a España neutral era la de permitir observar y prevenir las actividades del Abwehr montadas desde España. Dada

El coronel Beigbeder, ministro español de Asuntos Exteriores hasta octubre de 1940, y confidente de Hoare, le comunicó al embajador y éste a Londres los detalles de la reunión abortiva entre Franco e Hítler del 24 de octubre. Véase Hinsley, F. y otros, British Intelligence in the Second World War; its influence on Strategy and Operations, (Londres: His Majesty's Stationery Office, 1979), tomo 1, pág. 256.

8 Para una cronología de los principales acontecimientos diplomáticos anglo-hispanas entre junio de 1940 y abril de 1941 consúltese Morales Lezcano, V., Historia de la no-beligerancia española durante la segunda guerra mundial (Las Palmas: Ediciones del Cabildo Insular de Gran Canaria, 1995), págs. 54 y 63. 
la delicadeza de la situación, Hoare insistía en mantener un riguroso control sobre las actividades de los servicios secretos ingleses. Aquí su herramienta de control era el capitán de navío Alan Hillgarth, agregado de Marina en Madrid y persona de la confianza de Winston Churchill, jefe del Gobierno inglés. Durante la guerra civil española, Hillgarth había transmitido valiosas informaciones a Londres desde Palma de Mallorca, especialmente sobre los movimientos de buques de guerra italianos al servicio de Franco. Por otra parte, Hillgarth había desempeñado un papel relevante en facilitar la rendición de Menorca a Franco consiguiendo a la vez que fuerzas italianas no desembarcasen en aquella isla, rendición que el Gobierno inglés consideró como buen augurio de una mejora de relaciones con el victorioso general ${ }^{9}$.

A Hillgarth se le nombró agregado de marina en Madrid con el cometido de coordinar las actividades de la Información Naval, con las de la SIS y del nuevo organismo dedicado a sabotajes, el Secret Operations Executive, Agencia de Operaciones Secretas o SOE, creado el 22 de julio de 1940. Hillgarth era también responsable de sobornar a personajes importantes. Mientras tanto, el célebre armador y ex-contrabandista Juan March depositó importantes cantidades en la Swiss Bank Corporation de Nueva York, cuya finalidad era alentar el entusiasmo aliadófilo de ciertos generales ${ }^{10}$. Para noviembre de 1940 el Foreign Office aceptaba que «los generales. [son]... la fuente más probable de resistencia a la agresión alemana» ${ }^{11 .}$

Es difícil estimar el nivel de ayuda enviada por Inglaterra a los conspiradores, aunque Hillgarth indicó al coronel norteamericano Solberg, jefe del servicio secreto estadounidense (OSS), que Inglaterra apoyaba el golpe planificado por el general Aranda, anulado poco antes del desembarco aliado en Africa del Norte de noviembre $1942^{12}$.

Sin embargo, en diversas ocasiones desde Londres se echó una ducha de agua fría sobre los entusiasmos del embajador ${ }^{13}$. Habida cuenta de los

\footnotetext{
9 Sobre el papel de Hillgarth en la guerra civil española, véase ALPERT, Michael, La guerra civil en el mar (Madrid: Siglo XXI, 1987), págs. 348-351.

10 Sмүтн, Denis, «Les Chevaliers de Saint-George; la Grande-Bretagne et la corruption des généraux espagnols (1940-1942)", Guerres Mondiales et Conflits Contemporains, No. 162, abril de 1991, pags. 29-54. La cita original se encuentra en las memorias del ministro de Guerra Económica, Hugh Dalton, el cual se refiere, en la entrada correspondiente al 16 de mayo de 1941, a «la carga de los caballeros de San Jorge" (léanse las monedas de oro que portan tal divisa) SMrTH, Denis, Diplomacy..., pág. 226.

${ }_{11}$ Public Record Office, Foreign Office, General Correspondence (en adelante, PRO, FO371), C12266/40/41 del 15 de noviembre de 1940.

12 Harfis-SMITH, R. OSS (Berkeley and Los Angeles, University of California Press, 1972), pág. 78.

13 Entre otros mensajes véanse los archivados en PRO, FO371, C6021/222/41 del 3 de junio de 1941, C7410/33/41 del 4 de julio de 1941, y C8417/33/41 del 23 de julio de 1941.
} 
comentarios escépticos emanados desde Londres y la insistencia inglesa en no prometer nada de antemano, poco concreto se hizo. Anthony Eden, ministro de Exteriores, resumió la situación en una ponencia ante el Gabinete de Guerra, el 10 de noviembre de 1941:

«Sigo dudando de la posibilidad de un golpe de estado por los generales españoles en el futuro próximo, y dudo también si un cambio de régimen en España fuera ventajoso para nosotros, hasta que se aminore la influencia alemana y que el nuevo régimen esté en situación de realizar una política verdaderamente independiente [...]. Nos interesa dejar en su sitio a Serrano Súñer [ministro de Exteriores] ya que en todo caso no podemos ofrecer a España más [materias primas]» 14 .

Desde el verano de 1940 Inglaterra había reservado fuerzas con vistas a un desembarco en Canarias en caso de una declaración de guerra por parte de España. Cuando el 3 de noviembre de 1940 el Gobierno español suprimió la administración internacional de Tánger, zona que España había ocupado el 14 de junio, Churchill juzgó que había llegado el momento de tomar una decisión. Sin embargo, Hillgarth persuadió al jefe inglés de que la acción española en Tánger no anunciaba la entrada de España en la guerra ${ }^{15}$. No obstante, Hillgarth, por sus contactos en Madrid, estaba al tanto de los movimientos en Alemania de diversos jefes de la Marina española, sus compras y sus ofertas de construir buques submarinos en España para Alemania. En realidad, aunque el volumen de información era alto, había poca actuación concreta ${ }^{16}$. Sin embargo, todavía se juzgaba posible una invasión alemana de España, de modo que cuando Hillgarth fue a Londres en enero de 1941, el día 8 declaró ante el comité nacional de Defensa que en todo caso se debería buscar contacto con elementos de resistencia dentro de España, enviándoles un grupo de militares ingleses que les apoyara en caso de una invasión alemana ${ }^{17}$. Esto sería el origen de diversos programas de actuación inglesa en España. En el Almirantzago se estudiaron planes detallados a poner en vigor si fuera necesario, visualizando una posible cooperación con la Marina de Guerra española, actuaciones que suponen cierto nivel de confianza esta-

14 PRO FO371, C13225/33/41.

15 SMYTH, D., «Franco and the Allies in the Second World War» en Balfour S. y Preston P. (comps.) Spain and the Great Powers in the Twentieth Century (Londres: Routledge, 1999, págs. 185-210), págs. 195-196.

16 Véase PRO, documentos del Almirantazgo ADM223/805. El documento que hemos manejado corresponde a 1942, pero podemos suponer que las actividades a las cuales se refiere no eran menos cuantiosas anteriormente.

17 HINSLEY, tomo 1, pág. 257. 
blecida por Hillgarth, ya que se tratan de destrucciones, principalmente de instalaciones portuarias. Nada de eso, se embargo, llegó a comunicarse a las autoridades españolas ${ }^{18}$.

\section{$E L$ «SOE» EN ESPAÑA}

Dada la conocida desgana de Hoare para alentar movimientos subversivos en España, puede parecer extraña la recomendación de Hillgarth en el sentido de buscar contactos subversivos. En realidad, podemos suponer que el programa que el agregado de Marina recomendaba era mínimo. En el caso de un país neutral, evidentemente no era posible organizar un plan amplio de sabotajes tal como se iba preparando en la Europa ocupada, a ser realizados por el Special Operations Executive o SOE.

EI SOE fue creado en julio de 1940 después de la ocupación de la Europa occidental por los ejércitos alemanes, com el cometido de, en la expresión de Churchill, «set Europe ablaze» o «prenderle fuego a Europa» ${ }^{19}$. En la Península Ibérica las tareas del SOE incluían la evacuación de personal militar inglés que lograba escapar de la Europa ocupada, la distribución de propaganda subversiva, la organización de redes de agentes, y la preparación de sabotajes en caso de una invasión alemana o un golpe político que amenazase una alianza española con el Eje.

En Portugal y España, sin embargo, el trabajo subversivo amenazaba con poner en peligro la obra, generalmente tolerada por las autoridades, de los departamentos más antiguos de los servicios secretos ingleses. En estos círculos se consideraba a los jóvenes militares del SOE como advenedizos imprudentes, cuya inexperiencia les exponía a ser engañados por informantes de poco fiar ${ }^{20}$. En los dominios de Salazar y de Franco había que ir con pies de plomo, ya que la política del Foreign Office era de preservar el Status Quo. Precisamente, Hillgarth insistió en que el SOE excluyera a los «rojos» de sus planes ${ }^{21}$, si bien el SOE mantuvo relaciones

\footnotetext{
18 PRO, ADM 1-11339, 14 de febrero y 14 de septiembre de 1941; expediente No. 581 del Naval Intelligence Department.

19 La directiva constitutiva del SOE se encuentra en PRO, papeles del Gabinete CAB 80/56. Véase un estudio de la actividad del SOE en la vecina Portugal en WYLIE, N., «An amateur learns his job: Special Operations Executive in Portugal, 1940-1942", Journal of Contemporary History, 36 (3), julio de 2001, págs. 441-457.

20 JoHnS, Philip (jefe del SIS en Lisboa), Within Two Cloaks (Londres: Kimber, 1979), págs. 67-117 sobre Lisboa.

21 STAFFORD, David, Churchill and Secret Service (Londres: John Murray, 1997), pág. 209.
} 
elementales y oficiosas con redes secretas del ejército derrotado de la República. Sin embargo, en realidad, los documentos con referencia a la posibilidad de reconstituir unidades militares de la República, son tan escasos, que resulta evidente que todo se mantuvo en el más profundo secreto o en un estado embriónico de planificación ${ }^{22}$.

Después del desastre francés de 1940, las fuerzas militares evacuadas hacia Inglaterra incluían grupos sueltos de ex-soldados del Ejército Popular, evacuados desde Cataluña a Francia y luego movilizados. En el verano de 1940, Kim Philby se encontraba en Brickendonbury Hall, a unas veinte millas al norte de Londres, adquirido como centro de entrenamiento ${ }^{23}$. En aquel lugar había unos veinticinco españoles, principalmente dinamiteros asturianos. Más tarde, Philby sería responsable de construir un programa en las técnicas de sabotaje y de subversión, para el centro de formación del SOE ubicado en Beaulieu, en el condado de Hampshire ${ }^{24}$. En Beaulieu se encontraban los mismos españoles, los cuales le pusieron a Philby el mote de "comisario político», extraño título para una persona que ostentaba una condecoración franquista pero a la vez, y con cierta ironía dramática, enteramente apropiado para Philby que, detrás de una serie de velas de engaño, estaba al servicio de la URSS. Philby supone en su libro que se trataba del mismo grupo que más tarde conocería Peter Kemp, inglés ultra-derechista voluntario en el Requeté y en la Legión durante la guerra de España. Kemp cuenta en sus memorias como recibió un entrenamiento intensivo en las montañas de Escocia y en Gibraltar, cuya finalidad era prepararse, en el caso de que España declarara la guerra, para penetrar en territorio español vinculándose con guerrilleros españoles ${ }^{25}$. Este proyecto parece haber tenido algun aspecto de realidad, mientras otro, el llamado plan «Q», que sugería reclutar unos cincuenta militares del ejército republicano, incluso al capitán de Aviación Bayo, futuro guía de Fidel Castro, para realizar actividad guerrillera en el norte de España, nunca fue aprobado por las autoridades inglesas ${ }^{26}$.

Los proyectos para emplear a españoles anti-franquistas en caso de una declaración de guerra por parte de España o una invasión de territorio español por Alemania, no pasaron de ser preliminares. La Junta inglesa de

\footnotetext{
22 Sobre todo el expediente PRO HSi/254, pág. 19.

PHILBY, pág. 31.

PHILBY, págs. 37 y sigs.

Véanse sus obras No Colours or Crest (Londres: Cassell, 1958) y The Thorns of Memory (Londres: Sinclair-Stevenson, 1990). Philby, pág. 45.

26 PRO, HS6/914 del 22 de agosto de 1941. Véase sobre Bayo PRO, FO371 C11212/10222/41 del 18 de octubre de 1940 .
} 
Jefes de Estado Mayor había aprobado la creación de un grupo inglés el plan RELATOR - como núcleo de una resistencia guerrillera anti-alemana. Hoare, sin embargo, prohibió toda actividad militar secreta inglesa en España y desde luego toda relación con fuerzas hostiles al régimen franquista. Por esto las preparaciones no pasaron mucho más allá de la frontera de Gibraltar ${ }^{27}$. El grupo de Kemp, constituido por 18 militares ingleses hispanoparlantes, se reunió en el Peñón el 5 de abril de 1941. Se preparó un plan de destrucciones de carreteras y de ferrocarriles a realizar si fuerzas alemanas amenazaran con atacar a Gibraltar. El grupo permaneció unos meses en el Peñón, hasta que la operación fue abandonada en agosto de 1941. Aunque, en la primavera, las victorias alemanas en los Balcanes y en África del Norte, en Creta y en las primeras semanas de la campaña de Rusia, más el notorio discurso antibritánico de Franco, del 17 de julio, estimularon la idea de efectuar un golpe preventivo contra España, un estudio más cuidadoso del discurso del Caudillo llevó a una reconsideración ${ }^{28}$.

\section{EL NORTE DE ESPAÑA: OPERACIÓN REPROACH ${ }^{29}$}

El coronel Beigbeder, ministro de Exteriores sustituido en octubre de 1940 por Serrano Súñer, le había hablado a Hoare de la posibilidad de organizar fuerzas guerrilleras en Navarra contra una eventual invasión alemana. Hoare, viendo que esta vez se trataba de fuerzas de tradición carlista y no de la izquierda, estuvo de acuerdo y así se lo comunicó a Londres añadiendo que Inglaterra debería desembarcar pequeños grupos de militares en la costa del norte ${ }^{30}$. Para el 18 de agosto de 1941 los proyectos habían tomado forma. Un grupo de oficiales ingleses hispanoparlantes, los llamados "Sprinklers", iban a luchar con los Tradicionalistas, mientras otro, los «Sconces», ex-soldados de la República que habían luchado contra los alemanes en Noruega, harían causa común con los nacionalistas vascos o con los guerrilleros asturianos. Sin embargo, los documentos insistían, contradictoriamente, en que no podía permitirse ningún contacto directo con partidos políticos prohibidos, salvo con los Tradicionalistas. Se vislumbraba que en caso de una sublevación antifranquista,

\footnotetext{
27 West, Secret War, pág. 47.

${ }_{28}$ SMYTH, «Franco and the Allies...», págs. 202-203.

29 Véase PRO, HS6/938.

30 Templewood Papers (una colección de copias de despachos y otros papeles de Sir Samuel Hoare, luego Lord Templewood, depositados en la biblioteca de la Universidad de Cambridge), Caja XIII, sobre 21, documento 16. 1aa).
} 
Ios Tradicionalistas establecerían en Pamplona una estructura militar bajo el mando de "B", identificado como José Garmendia. De las conversaciones con los Tradicionalistas se concluyó que en caso de una invasión alemana, se organizaría, en combinación con los nacionalistas vascos, una resistencia guerrillera en Aragón, Cataluña y Valencia por mediación de «un cura batallador» («fighting priest») ${ }^{31}$.

Era evidente que Hoare deseaba que Hillgarth y otros jefes, incluso el capitán de fragata lan Fleming, futuro autor de los libros cuyo heroe sería el célebre James Bond, siguieran siendo el vínculo entre los ingleses y los Tradicionalistas. El dilema inglés queda patente en una carta de Hoare del 23 de agosto de 1941. Insistía el embajador en que era la ayuda económica inglesa la que mantenía neutral a España. La colaboración con fuerzas antifalangistas siempre corría el riesgo de provocar al Gobierno español. Hoare insistía en que no se debería infiltrar en España a agentes, propaganda subversiva ni «juguetes» (léanse armamentos y explosivos) sin su propio consentimiento.

En diciembre de 1941, el SOE se quejó ante la Junta de Jefes de Estado Mayor en Inglaterra de que la oposición de Hoare imposibilitaba realizar proyectos efectivos de resistencia. Después de largas discusiones en el Foreign Office y en la Junta de jefes de Estado Mayor, se decidió formar operadores de radio para operar en España, además de preparar un programa de abastecimiento de material de guerra. Además, se propuso invitar a españoles residentes en Inglaterra a ofrecerse como voluntarios para eventuales operaciones en España. El 24 de diciembre, se comunicó que Hillgarth había adquirido camiones y estudiaba cómo reunir cantidades de combustible.

Para marzo de 1942 un radio-operador polaco vivía en la casa del gobernador de la cárcel de Estella, dando la necesaria instrucción a dos españoles. Poco más se había hecho aunque el 14 de mayo de 1942 se anunció la llegada de setecientos fusiles automáticos y que se había establecido puntos donde aterrizarían paracaidistas. Se había impuesto grandes limitaciones en el empleo de aparatos de radio. Sin embargo, la seguridad de toda la operación era muy frágil y, el 8 de marzo de 1943, Hillgarth descubrió que el jefe del servicio falangista de Investigación e Información estaba al tanto de todo, informado por uno de los operadores de radio ${ }^{32}$. Durante la guerra civil esta persona, conocida por los ingleses

31 PRO, HS6/938 del 19 de agosto de 1941.

32 Normalmente los documentos que mencionan a personas por sus verdaderos nombres no están al alcance del público. En este caso puede tratarse de un error, por to cual preferimos callar el nombre y apellido en cuestión. 
como «Y», se había infiltrado en el Socorro Rojo Internacional, había sido desemmascarado y torturado. Escapando de la cárcel, había llegado a la Zona Nacional donde había seguido sus actividades secretas, esta vez al servicio de los sublevados. Sin embargo, mal tratado en un asunto donde él era inocente, era "fácil presa de los ingleses», según el informe falangista. «Requerida por un alto personaje monárquico», había creado milicias en Navarra y Guipúzcoa. Cuando el alto personaje le pidió que estudiara formas de poner en libertad a soldados aliados internados en el campo de Miranda del Ebro, "Y" se preguntaba — siempre según el informe falangista, por supuesto, arrimaba el ascua a su sardina antimonárquica- « ¿para quién trabajaba? Cuando se le contestó que una restauración monárquica era posible sólo colaborando con Inglaterra, "Y» decidió continuar trabajando en el "Intelligence Service» para sabotear los proyectos ingleses y pasar información sobre éstos a las autoridades militares españolas. En junio de 1943 Garmendia se encontraba bajo arresto domiciliario. La Falange efectuó una redada, que coincidió con una campaña desde el Gobierno contra los monárquicos ${ }^{33}$. En el contexto de la lucha entre Falange y monárquicos, parece que el informe falangista exageraba lo que no eran más que proyectos muy elementales ${ }^{34}$.

Era evidente el fracaso de los planes ingleses. El servicio de Información falangista había logrado infiltrarse entre los Tradicionalistas, enterándose de todos los detalles de la planificación inglesa, incluso los puntos de desembarco y de aterrizaje de aviones, depósitos de gasolina, claves de comunicación radiofónica, y planes de liberar a soldados aliados internados en Miranda.

Para el Foreign Office el momento era delicado. Los servicios secretos ingleses, temerosos de que el Foreign Office suprimiera todos los proyectos, insistieron en que los detalles descubiertos por la Falange eran un invento alemán para provocar tensión entre Inglaterra y España. Era afortunado que los alemanes no invadieran España, dado que las redes del único plan de resistencia habían sido desarticuladas.

\section{ACTIVIDADES DEL «MI6»: EL CONTRAESPIONAJE}

En Gibraltar mismo la seguridad constituía una máxima consideración por la presencia de tantos marineros y de españoles que atravesaban la 
frontera para trabajar en el arsenal. Tres saboteadores de barcos ingleses por 10 menos fueron detectados y, siendo ciudadanos ingleses, su traición atrajo la máxima pena ${ }^{35}$, mientras otros agentes practicaban sabotajes contra los barcos españoles que llevaban mercancías a Alemania ${ }^{36}$. A la vez que M/6 empleaba empresas de transporte que entraban y salían del Peñón para obtener información de toda la baja Andalucía, especialmente sobre el movimiento de unidades militares españolas en el Campo de Gibraltar, la Sección V observaba los conocidos agentes del enemigo, y otro departamento de la Informacióm Militar, el MI9, recibía, interrogaba y evacuaba a los prisioneros de guerra escapados y a los paisanos franceses, belgas y otros que lograban llegar a este territorio aliado ${ }^{37}$.

El encargado de la Sección $V$ en Gibraltar era Mr. Bristow ${ }^{38}$. Persona de ideas conservadoras, Bristow disentía cuando Londres deseaba que reclutara a personajes antifranquistas para formar grupos de guerrillas. Bristow creía que aun los más franquistas reaccionarían contra una invasión alemana. Habiendo descubierto que los alemanes escuchaban los mensajes emitidos por barcos ingleses desde una casa en la costa cerca de Algeciras, Bristow pidió permiso para montar una operación, haciendo saltar la casa. Pero esto supondría un saboteaje en territorio español, de modo que el Foreign Office prohibió la operación proyectada. Aun más importante, otro informante, jefe español de seguridad en el Campo de Gibraltar, pasó el mensaje de que el almirante Canaris, jefe del Abwehr, iba a celebrar una reunión en el Hotel Reina Cristina de Algeciras. Tres agentes ingleses pasaron unas horas tomando el té en el salón del hotel, observando a Canaris, pero, habiéndoseles prohibido el asesinato o captura que Bristow había propuesto a Londres, su actividad no pasó a mayores. Sin embargo, se logró la destrucción de una receptora-emisora alemana en Tánger, que enviaba mensajes a submarinos alemanes en el Estrecho. Hoare, después de ciertas dudas, dio su consentimiento a la operación, realizado en la madrugada del 10 de enero de $1942{ }^{39}$.

35 WEST, Nigel, MI5: British Security Service Operations 1909-1945 (Londres: the Bodley Head, 1981), págs. 299,303, 308.

36 PRO, HS 6/930 constituye un expediente muy repleto de documentos sobre la introducción de agentes en barcos mercantes españoles y portugueses.

37 Sobre MI9 véase NEAVE, A. Saturday at MI9 (Londres: Hodder and Stoughton, 1969) con muchas referencias, aunque escuetas, a las rutas por España que seguian soldados y paisanos que cruzaban los Pirineos.

38 Véase Bristow, D. y Bristow, B., A Game of Moles: the Deceptions of a MI6 Officer (Boston y Londres: Little, Brown \& Co, 1993), págs. 45-48,55, 68-71, 78-79.

39 PRO HS6/950 y 951 . 
Más positivas y muy del gusto del Foreign Office eran los éxitos del servicio inglés de contra-espionaje cuya finalidad era desenmascarar las actividades alemanas para poder demostrar al Gobierno español hasta qué punto los alemanes estaban abusando de la neutralidad española. Por ejemplo, en octubre de 1941, se ganó una baza iluminando con bengalas el reabastecimiento de combustible sin autorización en Cádiz del submarino alemán U564.

Otro éxito de la subsección encargada de acumular información en la Península fue la anulación de la operación alemana llamada BODDEN. Diversos informes indicaban que el Abwehr organizaba la instalación en Algeciras de dispositivos que detectaran el paso de barcos por el Estrecho durante la noche. Evidentemente, el que las autoridades españolas permitiesen tal actividad en suelo español constituía un acto contrario a su neutralidad. Lo importante no era destruir las instalaciones sino demostrar al Abwehr que el SIS estaba perfectamente al tanto de sus actividades, y por otra parte poner al gobierno español en una situación que creara tensión con los alemanes. El Foreign Office ordenó a Hoare presentar una protesta formal. El embajador hizo acto de presencia con sus consejeros y agregados, todos vestidos de uniforme diplomático, para protestar formalmente ante Franco, quien naturalmente no pudo menos que insistir en que el Gobierno alemán ordenara al $A b w e h r$ que pusiera fin a la operación Bodden ${ }^{40}$.

\section{ESPAÑOLES QUE ESPIABAN EN INGLATERRA A FAVOR DE ALEMANIA}

Quizás una de las más significantes y útiles contribuciones al trabajo de contraespionaje realizado en Londres y Madrid por el SIS y el MI5 lo constituía el desenmascaramiento de españoles, los cuales, ubicados en Inglaterra por motivos lícitos, realizaban tareas por cuenta del Abwehr. Uno de los primeros detenidos fue cierto Piernavieja del Pozo (las fuentes no indican su nombre) ${ }^{41}$, que llegó a Inglaterra en septiembre de 1940 en una visita de estudios respaldada por el Instituto de Estudios Políticos.

40 PHILBY, págs. 63-64. En realidad, la información sobre la operación Bodden provino de la intervención de emisiones radiotelegráficas alemanas por el servicio de intercepción llamado ISOS (Hirisley, tomo II, 1981, anexo 15, págs. 719 y sigs.).

41 Damos los apellidos porque han sido ampliamente mencionados en fuentes publicadas. 
Aprovechó las facilidades que le fueron dadas para enviar información escrita en tinta simpática en el verso de los informes que oficialmente enviaba a Madrid. Del Pozo no sabía que uno de sus contactos ingleses, Arthur Owens, doble agente que los alemanes creían tener a su servicio, mantenía al MI5 enterado de los movimientos de del Pozo, que tenían que ver con la productividad de fábricas de armamentos en el País de Gales, donde su guía era otro fingido agente de Alemania. Este era Gwilym Williams, inspector de policía jubilado y afiliado, por lo menos tal era la ficción construída, al movimiento nacionalista galés, al cual los alemanes creían un posible futuro aliado ${ }^{42}$.

Durante estas semanas se creó el llamado $X X$ Committee ${ }^{43} . \mathrm{El}$ $X X$ Committee se encargaba de "tornar" a los agentes enemigos, comunicándoles noticias militares falsas para que las transmitiesen a Berlín ${ }^{44}$. En mayo de 1941 el agente Williams se puso en comunicación con Luis Calvo, corresponsal de un diario madrileño destacado en Londres y conocido como espía. Éste siguió hasta 1942 reuniéndose con Williams y recibiendo información, falsa por supuesto. Por otra parte, no dudando que Williams fuera como él un espía a favor de Alemania, Calvo le habló del jefe de la red español de espionaje pro-alemán en Inglaterra. Este era Angel Alcázar de Velasco, destacado falangista, que ostentaba el cargo de agregado de prensa de la embajada española, pero cuya cajafuerte en Madrid había sido abierta por el SIS. Examinados los documentos que la cajafuerte contenía, la conclusión inglesa fue que la red de agentes que Alcázar de Velasco describia en los documentos que comunicaba al $A b$ wehr era imaginaria, creada para impresionar y sacar fondos de los alemanes ${ }^{45}$. Sin embargo, la información descubierta permitió detener a Calvo, atemorizario sin tener que echar mano de métodos brutales, y persuadirle que siguiera pasando la información que le proporcionara el MI5.

La opinión de Philby, desde su atalaya londinense como jefe de la sección ibérica, era que «pocos españoles y portugueses se mostraban entusiastas para arriesgar la cabeza por el fascismo. Muchos de los que aceptaban misiones lo hicieron simplemente para salir de la Península o entrar en Inglaterra o las dos cosas» ${ }^{46}$. Como ejemplo, Philby cuenta la historia

\footnotetext{
42 Véase HowARD, Michael, British Intelligence in the Second World War, tomo V (Londres: HMSO, 1990), pág. 4.

$43 X X$ significba "doble cruz», expresión que en inglés indica engaño.

44 Masterman, J.C., The Double Cross System in the War of 1939 to 1945 (New Haven: Yale University Press, 1972)

45 Sobre las actividades de Alcázar de Velasco, véase PRO FO 371,C2423, C5611/376/41.

46 PhILbY, pág. 89.
} 
del portugués Ernesto Simoes. A este obrero especializado se le había concedido un permiso de trabajo en una fábrica de aviones, pero uno de los decenas de miles de mensajes radiotelegráficos alemanes interceptados, reveló que Simoes había sido reclutado por el Abwehr. El MI5 le detuvo, pero resultaba que vivía bien, ganando unos jornales altos en la fábrica y gozando de los favores de la señora en cuya casa tenía alquilada una habitación ${ }^{47}$. No tenía interés en arriesgar su cómoda situación haciendo espionaje. Otro de los españoles, empleado en el departamento de prensa de la embajada, José Brugada Wood, actuaba como canal de mensajes. Detenido, fue "persuadido" a que siguiera enviando mensajes, esta vez sutilmente falsificados, sobre la producción de aviones ${ }^{48}$.

Estas personas y otras llegaron a ser autores convincentes de una cantidad ingente de material falso sobre localización de unidades militares, aspectos técnicos de cañones, defensa contra paracaidistas etc, regularmente comunicado a Alemania, de manera que, leyendo las preguntas que los alemanes enviaban, el XX Committee y el MI5 podían incluso averiguar las intenciones del enemigo ${ }^{49}$.

Mientras tanto, el $X X$ Committee preparaba uno de los mayores actos de engaño de los alemanes realizado en la Segunda Guewrra Mundial, llamado Operación Mincemeat.

\section{MINCEMEAT, O «EL HOMBRE QUE NUNCA EXISTIÓ»}

Esta operación ${ }^{50}$ se basaba en "plantear» en un cadáver unos planes falsos de operaciones, con la esperanza de que los alemanes creyeran que los documentos representaban las intenciones de los aliados. Se ideó el plan de abandonar un cadáver de tal manera que las autoridades españolas lo rescataran, entregando a los alemanes los documentos que llevaba. El 4 de febrero de 1943 se encontró un cadáver -empresa acompañada de cierta dificultad, ya que el cadáver debería ser de una persona cuyos familiares no reclamaran sus restos y que por su edad y otras condiciones podría ser convincentemente vestido de militar y cuya verdadera causa de muerte no era evidente. Luego había que crearle una personalidad- se inventó el personaje del mayor Martin, de Infantería de Marina,

\footnotetext{
7 Hinsley, tomo IV, pág. 336; Philby, pág. 89.

48 Masteriman, pág. 113; West, MI5, pág. 182; PhilbY, pág. 57.

49 Masterman, págs. 72, 83-84, 121.

50 El episodio ha sido contado por MonTagu, E., The Man who Never Was (Londres: 1953).
} 
destacado en el Estado Mayor del Jefe de Operaciones Conjuntas, el almirante Mountbatten - proporcionarle documentación y efectos personales, y finalmente, antes de echarle al agua desde un submarino en aguas de Huelva donde las corrientes le llevarían a la costa y donde se sabía que el vice-cónsul alemán era muy eficaz, llenarle los pulmones de agua, ya que había que demostrar que había muerto ahogado. Las cartas ficticias que llevaba el «mayor Martin» deberían persuadir a los alemanes de que los anglo-americanos iban a efectuar un desembarco en Grecia, cuando el verdadero objetivo era Sicilia. El cadáver fue encontrado a la altura de Huelva. Antes de entregarlo al capitan Hillgarth, como era preceptivo, las autoridades españolas abrieron la cartera que venía fijada con esposas a la muñeca del cadáver, extrajeron las cartas, las copiaron y entregaron al $A b$ wehr. Desde Inglaterra, los servicios de descodificación siguieron el progreso del informe del Abwehr. Efectivamente, el alto mando alemán quedó convencido de la autenticidad de los documentos. Por éste y otros motivos, el desembarco aliado en Sicilia encontró a aquella isla mal defendida ${ }^{51}$.

\section{LA CONTRIBUCIÓN A LA VICTORIA ALIADA DE «GARBO»}

El más célebre de todos estos agentes era, sin duda, el llamado «Garbo» ${ }^{52}$. Su gran contribución a la victoria aliada llegaría en junio de 1944. "Garbo" era un catalán, Juan Pujol García, de 29 años de edad, muy desilusionado con los regímenes totalitarios después de su experiencia en la guerra civil española. Concibió la idea de ofrecerse como agente secreto a las autoridades inglesas. Rechazado por la embajada inglesa en Madrid en enero de 1941, logró persuadir al Abwehr de que el Gobierno español le iba a mandar pronto a Londres, por lo cual los alemanes le reclutaron, dándole tinta simpática y una dirección adonde enviar sus informes. Pero Pujol no fue a Londres sino a Lisboa donde, armado con un mapa del Reino Unido, una guía turística, unos detalles de la Armada inglesa y un léxico de términos militares, en el espacio de casi un año in-

51 La historia del «mayor Martin» ha tenido una última carambola. El médico forense que reconoció el cadáver supo en seguida que no había muerto ahogado. Sin embargo, como los agentes alemanes de la región sabían de las simpatías pro-aliadas del médico, concluyeron que hacía su alegato para sugerir que los documentos que llevaba el cadáver eran ficticios cuando los alemanes los creían auténticos, enredo que ni siquiera el Secret Service hubiera podido inventar! Véase Burns Marañón, T., Hispanomanía (Barcelona: Plaza y Janés, 2000), págs. 19-20.

52 Se han publicado los mensajes falsos enviados por Garbo, y su historia, escrita para SIS por su controlador, el tratante de cuadros, medio español, Tomás HaRRIs, Garbo, the Spy who saved D-Day, introducción de Mark Seaman (Londres: Public Record Office, 2000). 
ventó cuarenta informes basados sobre sus propias "observaciones» y las de unos subagentes ficticios. En Londres, al leerse los mensajes del Abwehr que pasaban por radio entre Madrid y Berlín, eran conscientes de que los alemanes daban plena confianza a lo que les comunicaba Garbo, a quien los alemanes denominaban Arabel. Éste incluso hablaba de estibadores de Glasgow preparados a hacer cualquier cosa a cambio de un litro de vino (!En un país donde el vino tinto era casi desconocido!) ${ }^{53}$. No es sorprendente que el prestigio del $A b w e h r$ en esferas militares alemanas no fuera muy alto.

En marzo de 1942 Pujol reveló su identidad a un agente del M/6 en Lisboa. Evidentemente había que unificar criterios; los informes de Pujol no deberían contradecir los de otros agentes dobles controlados por el MI5 desde Inglaterra. Entonces se trajo a Pujol a Londres en abril de 1942. Desde Inglaterra Garbo y su control, el experto en arte español Tomás Harris, engañaron al Abwehr durante el resto de la guerra por medio de una red extensa de agentes ficticios, siendo su mayor hazaña la de haber decepcionado a los alemanes sobre la verdadera punta de lanza del desembarco aliado en Francia el día 6 de junio de 1944.

\section{CONCLUSIONES}

Hay muchos otros aspectos a tratar de la actuación de los servicios secretos ingleses en España durante la Segunda Guerra Mundial, sobre todo en cuanto a operaciones en el Estrecho, a la altura de Gibraltar y en Tánger, puntos neurálgicos de la actuación alemana, y sobre el empleo de territorio español para establecer líneas de evasión de personal aliado huído de la Europa ocupada.

Evidentemente, Inglaterra estaba mal preparada para la posibilidad de una invasion alemana de España. Más posibilidad había de un golpe militar realizado por los generales antifranquistas, aunque el Foreign Office era consciente de que no podía fundamentar una política tan delicada como la española sobre el variado estado de ánimo, diversas querencias políticas y, más que nada, la franqueza y aparente incapacidad de los generales de guardar el secreto.

Hoare, desde el punto de vista inglés, hostil a cualquier sugerencia de alentar una sublevación antifranquista, se oponía a los que querían em-

53 Howard, págs. 18-20. 
plear guerrilleros reclutados entre los antifranquistas que vivían en el exilio, pero hemos visto incluso que la seguridad de la operacion tradicionalista Reproach, respaldada por el capitán de Navío Hillgarth y aprobada por Hoare, era tan deficiente que fue desarticulada por la Falange. En realidad, lo que impidió la entrada de España en la guerra fue el propio interés de España y el bloqueo marítimo mantenido por la Marina Real. Mientras tanto, Inglaterra mantuvo una constante presión diplomática y propagandistica, ganando de vez en cuando bazas demostrando que Alemania abusaba de la neutralidad española. Probablemente el mayor triunfo de los servicios secretos ingleses lo constituían la identificación de españoles que hacían espionaje en Londres a favor de los alemanes, y el empleo de agentes dobles, sobre todo Garbo. 